\title{
A CHRONOLOGY OF THE VERY EARLY HISTORY OF INHALATION ANAESTHESIA IN CANADA
}

\author{
Aкitomo Matsuki, M.D. ${ }^{*}$
}

Although SEVERAL WELL DOCUMENTED ARTICles ${ }^{1-7}$ are available on the history of surgical anaesthesia in Canada, it has not been fully elucidated when information about ether anaesthesia was first brought from the United States to Canada. Furthermore, the available sources contain conflicting reports as to who administered the first surgical anaesthetic with ether and chloroform, as well as the first obstetrical anaesthetic.

Fuller $^{2}$ states that Dr. Almon was the first to use chloroform for surgical anaesthesia; yet Shields ${ }^{5}$ attributes the first chloroform anaesthetic to Dr. A.F. Holmes.

According to a recent article by Jacques, ${ }^{6} \mathrm{Dr}$. Worthington was the first to administer both ether and chloroform during surgical operations.

McKenzie $^{1}$ and Fuller ${ }^{2}$ report that a chemist, Frazer, of Nova Scotia, administered chloroform to his wife during delivery and that consequently this was the first obstetrical anaesthetic. However, Heagerty ${ }^{3}$ credits Dr. Holmes with its first use for parturition in Canada. Thus it is still unclear exactly when, where and who administered the first surgical and obstetrical anaesthetics with ether or chloroform in Canada.

It seems appropriate therefore to provide a chronology of the history of early surgical anaesthesia in Canada, in the hope that this may be helpful to future historians.

November, 1846. Information on ether anaesthesia is brought to Canada.

The British American Journal of Medicine and Physical Science (Brit. Amer. J. 2: 226, 1846 Dec. 1, 1846) announces in the column of "Books etc. Received during the Month" that they have received the November issue of the Boston Medical and Surgical Journal which includes H.J. Bigelow's paper on ether anaesthesia.

January, 1847. First mention of ether anaesthesia appears in Canadian Medical Journal.

First mention of ether anaesthesia entitled "Insensibility During Surgical Operations Produced by Inhalation" appears in a Canadian Journal. This is an extract from the December (1846) issue of the Philadelphia Medical Examiner. (Brit. Amer. J. 2: 247 (1847).)

\footnotetext{
'Instructor, Department of Anesthesiology, University of Hirosaki School of Medicine, Aomori-Ken, Japan. Previously research associate, Department of Anesthesiology, University of Michigan Medical Center, Ann Arbor, Michigan.
} 
January, 1847. Dr. Nelson begins experiments with ether anaesthesia.

Mr. Webster, a dentist of Montreal, purchases an ether inhaler from a "chevalier d'industrie." Mr. Webster and Dr. Horace Nelson begin experiments with ether anaesthesia using dogs and also administer it to each other. (Brit. Amer. J. 3: 34 (1847).)

March, 1847. Dr. J. Douglass employs ether for the amputation of toes (the first use of ether anaesthesia in Canada).

Dr. James Douglass of Quebec amputates the toes of a man under ether anaesthesia. This anaesthetic precedes the one to Dr. Nelson's patient. (Brit. Amer. J. 2: $338(1847)$.)

March, 1847. Mr. Webster successfully administers ether to Dr. Nelson's patient.

Dr. Wolfred Nelson (Horace Nelson's father) succeeds in removing a large tumour from a woman. Mr. Webster anaesthetizes her with ether. The date of the operation is unknown, but took place before March 8, 1847. (Brit. Amer. J. 3: 34 (1847).)

March 11, 1847. Dr. Worthington employs ether anaesthesia.

Dr. Worthington of Sherbrooke amputates the foot of a 30 -year-old man using ether anaesthesia. He employs a large ox-bladder with a stop-cock as an inhaler. (Brit. Amer. J. 3: 10 (1847).)

March, 1847. Dr. Campbell's failure with ether anaesthesia.

Dr. Campbell fails to anaesthetize a patient with ether at the Montreal General Hospital. (Brit. Amer. J. 2: 338 (1847).)

March, 1847. Editorial on anaesthesia appears in Brit. Amer. J.

The editorial "Inhalation of Sulphuric Ether Vapour" appears in the March issue of the British American Journal. (Brit. Amer. J. 2: 304 (1847).)

September 6, 1847. Dr. Crawford uses ether for tetanus.

Dr. J. Crawford of McGill College uses ether for sedating a patient with traumatic tetanus. (Brit. Amer. J. 3: 199 (1847).)

November, 1847. Dr. J. Crawford administers successful ether anaesthesia.

Dr. J. Crawford uses ether anaesthesia successfully for the amputation of the leg of a 14-year-old boy at the Montreal General Hospital. (Brit. Amer. J. 3: 199 (1847).)

January 24, 1848. Dr. Worthington uses chloroform (the first use of chloroform anaesthesia in Canada).

Dr. E.D. Worthington of Sherbrouke employs chloroform to alleviate pain during the manual reduction of a fracture of the femur in an old woman. The pain relief is only partial. (Brit. Amer. J. 3: 326 (1848).) 
January $25,1848$.

Dr. E.D. Worthington succeeds in removing a tumour from the right hand of a child under chloroform anaesthesia. (Brit. Amer. J. 3: 326 (1848).)

January 25, 1848. Dr. Holmes gives successful obstetrical anaesthesia with chloroform (the first use of chloroform for childbirth in Canada).

Dr. A.F. Holmes, Professor of the Theory and Practice of Medicine, McGill College, Montreal, uses chloroform anaesthesia successfully in a case of parturition. (Brit. Amer. J. 3: 263 (1848).)

January, 1848. Dr. Sutherland administers chloroform anaesthesia in Montreal.

Dr. Sutherland of the Montreal General Hospital performs anaesthesia successfully. The operation took place between January 23 and January 29. (Brit. Amer. J. 3: 278 (1848).)

February 1, 1848. Dr. Almon administers chloroform anaesthesia.

Dr. W.J. Almon of Halifax amputates the thumb of a woman under chloroform anaesthesia in the presence of Dr. Parker and Dr. Brown. (Canad. Med. Assoc. J. 14: 254 (1924).)

February 3, 1848. Dr. Martin reports three cases of chloroform anaesthesia. Dr. J. Martin of the Quebec Marine Hospital performs three operations under chloroform anaesthesia.

The first two are amputations of the great toes of Francis McNamara, aged 18 and Denis O'Hara aged 16. The third is an amputation of both legs of Adam Belte, a French sailor. (Brit. Amer. J. 3: 325 (1848).)

February 4, 1848. Dr. Marsden mentions two cases of chloroform anaesthesia.

Dr. W. Marsden of Quebec reports two cases of chloroform anaesthesia. The first case is an amputation of both legs of Pierre Francois Lamane, aged 33, by Dr. J. Douglass and Dr. A. Sewell. The second case is a tonsillectomy performed on a 14-year-old boy by Dr. J. Douglass. (Brit. Amer. J. 3: 288 (1848).)

February 12, 1848. Dr. Nelson undertakes lithotomy during chloroform anaesthesia.

Dr. W. Nelson of Montreal performs a lithotomy on a man aged 65 under chloroform anaesthesia. Dr. Arnoldi and Dr. Sutherland assist at the operation. (Lancet, 1: 380 (1848).)

February 15, 1848. Dr. Johnstone uses chloroform for delivery.

Dr. James B. Johnstone of Sherbrooke reports three cases of chloroform anaesthesia during parturition. (Brit. Amer. J. 3: 324 (1848).)

March 10, 1848. Dr. Almon's chloroform anaesthesia.

Dr. W.J. Almon of Halifax amputates the leg of a woman under chloroform anaesthesia. (Canad. Med. Assoc. J. 14: 254 (1924).) 
March 22, 1848. Dr. Frazer administers chloroform to his wife.

A chemist, D.B. Frazer of Pictou, Nova Scotia, administers chloroform to his wife during delivery. Chloroform used is manufactured by himself. (Canad. Pharmaceutical J. 58: 118 (1924).)

May 31, 1848. Dr. Campbell's chloroform anaesthesia.

Dr. Duncan Campbell removes a breast tumour under chloroform anaesthesia. (Canad. Med. Assoc. J. 32: 84 (1935).)

February 1, 1858. First anaesthetic death in Canada.

Mr. John McChesney dies suddenly following chloroform anaesthesia in the operating room of Dr. French of Montreal. This is the first death under chloroform anaesthesia. (Medical Chronicle 5: 425 (1858).)

\section{REFERENCES}

1. MacKenzie, K.A. Early adventures with chloroform in Nova Scotia. C.M.A.J. 1928, 14: 254-255 (1924).

2. Fuller, R.C. \& AMHEnst, N.S. The first anaesthetic record of the use of chloroform on this side of the Atlantic. Canad. Pharaceu. J. 58: 118-119 (1924).

3. Heagerty, J.J. Four centuries of medical history in Canada. Macmillan 1928. Vol. 1, pp. 304-307.

4. Colebeck, W.K. The first record of an anaesthetic in Ontario. C.M.A.J. 32: 84-85 (1935).

5. Shrelds, H.J. The history of anaesthesia in Canada. Canad. Anaes. Soc. J. 2: 301-307 (1955).

6. JacQues, A. The Hotel Dieu de Québec. 1634-1964. Anaesth. Analg. 45: 15-20 (1966).

7. Ibid: anaesthesia in Canada 1847-1967. The beginning of anaesthesia in Canada. Canad. Anaes. Soc. J. 14: 500-509 (1967). 